\title{
Comportamento da qualidade fisiológica de sementes de Capororoca-do-Banhado (Myrsine parvifolia A. DC. - Primulaceae) em diferentes tempos e condições de armazenamento
}

\author{
Leandro Dal Ri, Anaíse Costa Calil, Luiz Carlos da Silva \& Daiana Roubaldo Müller
}

Fundação Zoobotânica do Estado Rio Grande do Sul, Jardim Botânico, Banco de Sementes, Av. Dr. Salvador França, 1427, CEP 90960-000, Porto Alegre. dalri2010@gmail.com

Recebido em 12.X.2014

Aceito em 20.XI.2017

DOI 10.21826/2446-8231201772310

RESUMO - A qualidade fisiológica de sementes de Myrsine parvifolia A. DC. foi avaliada a partir de unidades de dispersão recém-colhidas e posteriormente armazenadas por 360 dias em câmara fria seca (cfs) $\left(17^{\circ} \mathrm{C} \pm 2^{\circ} \mathrm{C}\right.$ e $\left.\approx 45 \% \mathrm{UR}\right)$ e em câmara fria úmida $(\mathrm{cfu})\left(5^{\circ} \mathrm{C} \pm 2^{\circ} \mathrm{C}\right.$ e $\approx 80 \%$ UR). Todos os testes de emergência de plântulas foram conduzidos em Casa de Vegetação, onde as variações de temperatura e umidade do ar eram ditadas pelo ambiente externo. As sementes recém-colhidas apresentaram $43,4 \%$ de teor de água (Ta) e $86 \%$ de germinação (G); sementes armazenadas em cfs, ao longo do experimento sofreram uma redução de cerca de $75 \%$ do Ta inicial, sem, no entanto, perderem a viabilidade. As sementes mantidas em cfs e em cfu, ao longo dos 360 dias do experimento, mantiveram a viabilidade, entretanto, observou-se uma gradual redução na germinação de $86 \%$ para $64 \%$. Quanto à tolerância à dessecação, as sementes desta espécie apresentaram comportamento intermediário.

Palavras-chave: armazenamento, armazenamento de sementes

\begin{abstract}
Evaluation of physiological seed quality of Myrsine parvifolia A. DC. (Primulaceae) at different storage conditions. The physiological quality of seeds of Myrsine parvifolia A. DC. stored at dry cold chamber $\left(17^{\circ} \mathrm{C} \pm 2^{\circ} \mathrm{C}\right.$ and $\left.\approx 45 \% \mathrm{RH}\right)$, and in the wet cold chamber $\left(5^{\circ} \mathrm{C} \pm 2^{\circ} \mathrm{C}\right.$ and $\approx 80 \% \mathrm{RH}$ ) was evaluated. All germination tests were conducted at a Greenhouse, where variations in temperature and air humidity were dictated by the external environment. The newly harvested seeds had $43.4 \%$ of water content and $86 \%$ of germination. Seeds stored in dry cold chamber suffered a reduction of about $75 \%$ of the initial water content, however, not losing germination viability. Seeds in both conditions, throughout the 360 days of the experiment, maintained viability, with a gradual reduction in germination, declined from $86 \%$ to $64 \%$ at the end of storage period. Regarding the desiccation tolerance in relation of germination, the seeds showed intermediate behavior, neither completely tolerant nor intolerant.
\end{abstract}

Keywords: seed germination, seed storage

\section{INTRODUÇÃO}

A Capororoca-do-banhado (Myrsine parvifolia A. DC.) cresce espontaneamente nas Regiões Nordeste (BA), Sudeste e Sul do Brasil, distribuindo-se por tipos vegetacionais distintos, desde campos rupestres e Florestas Ombrófilas dos domínios da Mata Atlântica, bem como no Cerrado (Freitas 2014).

De hábito arbustivo, M. parvifolia apresenta-se bastante ramificada, com cerca de três metros de altura quando adulta. Floresce entre outubro a dezembro, tendo frutos maduros durante o período de fevereiro a julho (Jung-Mendaçolli \& Bernacci 2001). A polinização em M. parvifolia é realizada pelo vento, seguindo padrão de polinização anemófilo encontrado em Myrsine spp. (Albuquerque et al. 2013). Conforme Barroso et al. (1999) os frutos drupoides, formados pelas espécies brasileiras pertencentes a família Myrsinaceae (atualmente em Primulaceae) são globosos, carnosos e indeiscentes, bastante semelhantes entre si. No caso das espécies de Myrsine L., os frutos são reunidos em glomérulos sésseis e densos, ao longo e ao redor dos ramos.
As espécies de Myrsine L., comumente denominadas de capororocas, apresentam grande importância ecológica e fitofisionômica, sendo que em determinados estágios de desenvolvimento de florestas secundárias tornam-se dominantes (Reitz et al. 1988). Em áreas abandonadas pela agricultura e pastagem, tais espécies apresentam comportamento pioneiro (Carvalho 2003, Rego et al. 2009), bem como podem agir como secundárias iniciais, com relatado por Vaccaro et al. (1999). Espécies de capororocas produzem grande quantidade de frutos, que são consumidos por aves e mamíferos (Rego et al.2009), tornando-se espécies chaves nos ecossistemas em que crescem. No que diz respeito à frugivoria, Pascotto (2007) relatou que 31 espécies de aves consumiram frutos de M. coriaceae (Sw.) R.Br. ex Roem \& Schult, sendo que 25 destas são possíveis dispersores de propágulos da planta, e Jesus \& Monteiro-Filho (2007) relacionaram 22 espécies de aves consumidoras de frutos de M. coriaceae, todas potenciais dispersoras.

Avaliações do comportamento das sementes frente à dessecação, bem como testes de germinabilidade, 
emergência de plântulas e potencial de armazenamento são fundamentais para poder inferir sobre o ambiente ecológico em que a espécie evoluiu e se encontra atualmente. Tais avaliações também são importantes nos programas de produção de mudas e recuperação ambiental. Salvo alguns poucos experimentos e algumas considerações sobre o comportamento de sementes de Myrsine spp. (Joly \& Felippe 1979, Queiroz \& Fiamoncini 1989, Carvalho 1994, Fowler \& Bianchetti 2000), nenhuma abordagem científica, levando em conta a viabilidade de armazenamento foi realizada, até o momento. O presente trabalho contribui para o conhecimento do comportamento das sementes de M. parvifolia, quando armazenadas em diferentes condições de temperatura e umidade relativa do ar.

\section{MATERIAL E MÉTODOS}

O experimento foi conduzido no Laboratório de Análise de Sementes (LAS) do Banco de Sementes do Jardim Botânico de Porto Alegre, Fundação Zoobotânica do Rio Grande do Sul (FZB/RS). Os frutos foram coletados no município de Torres, no Parque Estadual de Itapeva em 27 de abril de 2011, em exemplares arbóreos de Myrsine parvifolia crescendo a pleno sol, na região das dunas da linha litorânea.

Com auxílio de uma lupa binocular com 32x de magnificação, os pirênios contidos no Mostruário Científico do Banco de Sementes, serviram de base para a descrição macro morfológica, que seguiram a terminologia adotada por Barroso et al. (1999), Lorenzi \& Gonçalves (2011) e Martin (1946).

Os frutos foram beneficiados manualmente, em água corrente, retirando-se as impurezas e envoltórios externos das drupas, ou seja, epicarpo e mesocarpo. Procedeu-se a determinação do teor de água (Ta) inicial, base peso úmido, a partir de 2 amostras de 30 sementes, dispostas em estufa à temperatura $105^{\circ} \mathrm{C} \pm 3^{\circ} \mathrm{C}$, durante 24 horas, conforme Brasil (2009) e Lima Junior (2011).

Os testes de germinação $(\mathrm{G})$, levando em conta as plântulas emergidas, foram conduzidos em Casa de Vegetação, sobre substrato de areia + fibra triturada de exocarpo de coco, na proporção 1:2 v/v. Em cada experimento foram estabelecidas 4 repetições de 25 sementes. Os procedimentos, padronizados, seguiram as recomendações de Brasil (2009) e Lima Junior (2011).

Após a retirada de amostras de sementes para as avaliações iniciais, o lote restante foi homogeneizado e dividido em duas partes, sendo que uma destas partes foi armazenada em sacos de papel pardo tipo Kraft, em câmara fria seca (cfs), à temperatura de $17^{\circ} \mathrm{C} \pm 2^{\circ} \mathrm{C} \mathrm{e} \approx$ $45 \%$ UR, e outra parte foi armazenada em plásticos de polietileno semipermeável em câmara fria úmida (cfu) à temperatura de $5^{\circ} \mathrm{Ce} \approx 80 \%$ UR. Ensaios de germinação pós-armazenamento foram realizados, levando em conta períodos de 60, 120, 180, 240, 300 e 360 dias.

As avaliações da germinação em Casa de Vegetação, com contagem de plântulas emergidas, foram realizadas a cada três e quatro dias, alternadamente, durante 220 dias. Os parâmetros avaliados no experimento foram: i) Germinação percentual ( $G \%)$, tendo como critério a emergência das partes aéreas, tais como a alça do hipocótilo, o epicótilo e/ou cotilédones e primeiro par de folhas; ii) Índice de velocidade de germinação (IVG), iii) Tempo médio de germinação (TMG), e iv) Emergência acumulada de plântulas, seguindo as fórmulas e parâmetros de cálculo considerados por Borguetti \& Ferreira (2004), Brasil (2009) e Lima Junior (2011).

A análise das médias entre os tratamentos foi realizada com o auxílio de o pacote estatístico WinPepi versão 11.65, valendo-se do programa COMPARE2, módulo F1. Os dados foram considerados como sendo categóricos em duas condições: i) sementes germinadas versus ii) sementes não germinadas, para cada experimento considerado. Para as comparações utilizou-se o teste qui-quadrado $\left(\chi^{2}\right)$, observando-se os resíduos ajustados, a fim de identificar quais tratamentos apresentaram diferença estatisticamente significante $(p<0,05)$, mediante a comparação da média do tratamento versus a média geral.

\section{RESULTADOS E DISCUSSÃO}

Os frutos drupoides de M. parvifolia, recebidos pelo Banco de Sementes em 19 de abril de 2011, apresentavam coloração escura, indicando o estado de maturidade completa dos mesmos (Fig. 1A). Pirênios globosos, com base acuminada e endocarpo cartáceo de superfície externa castanho-clara com presença de fibras mesocárpicas em sua superfície dispostas em arranjo semelhante a meridianos (Fig. 1b); presença de endosperma branco-amarelado, firme, apresentando cavidades superficiais irregulares onde se encontram rudimentos seminais abortados; embrião axial transversal, linear a levemente curvo; dimensões dos pirênios: 3,5-4,5 mm diâmetro.

Os resultados da germinação $(\mathrm{G} \%)$ referente aos experimentos realizados estão contidos na Tabela 1. Os testes iniciais e os experimentos $120 \mathrm{cfs}, 180 \mathrm{cfs}$ e $240 \mathrm{cfu}$ apresentaram médias estatisticamente significativas, acima da média geral, ou seja, o armazenamento das sementes em cfs por até 180 dias e em cfu por 240 dias afetaram positivamente a germinação. Somente o tratamento $300 \mathrm{cfs}$ apresentou resultado significativamente inferior a media geral (71\%), demais tratamentos não diferem estatisticamente desta média, inclusive aqueles realizados aos 360 dias de armazenamento, indicando que ocorreu uma manutenção do poder germinativo comparável àquela dos testes iniciais (Tab. 1).

Foi constatada a manutenção do poder germinativo ao longo dos 360 dias do experimento, independentemente da condição de armazenamento, ocorrendo uma natural redução do poder germinativo da ordem de $16 \%$ em 360 cfu e $22 \%$ em 360 cfs, quando comparados com o a média dos testes iniciais (Fig. 2).

Chama a atenção o fato de que sementes armazenadas por 60 dias, independente da condição cfs ou cfu, 


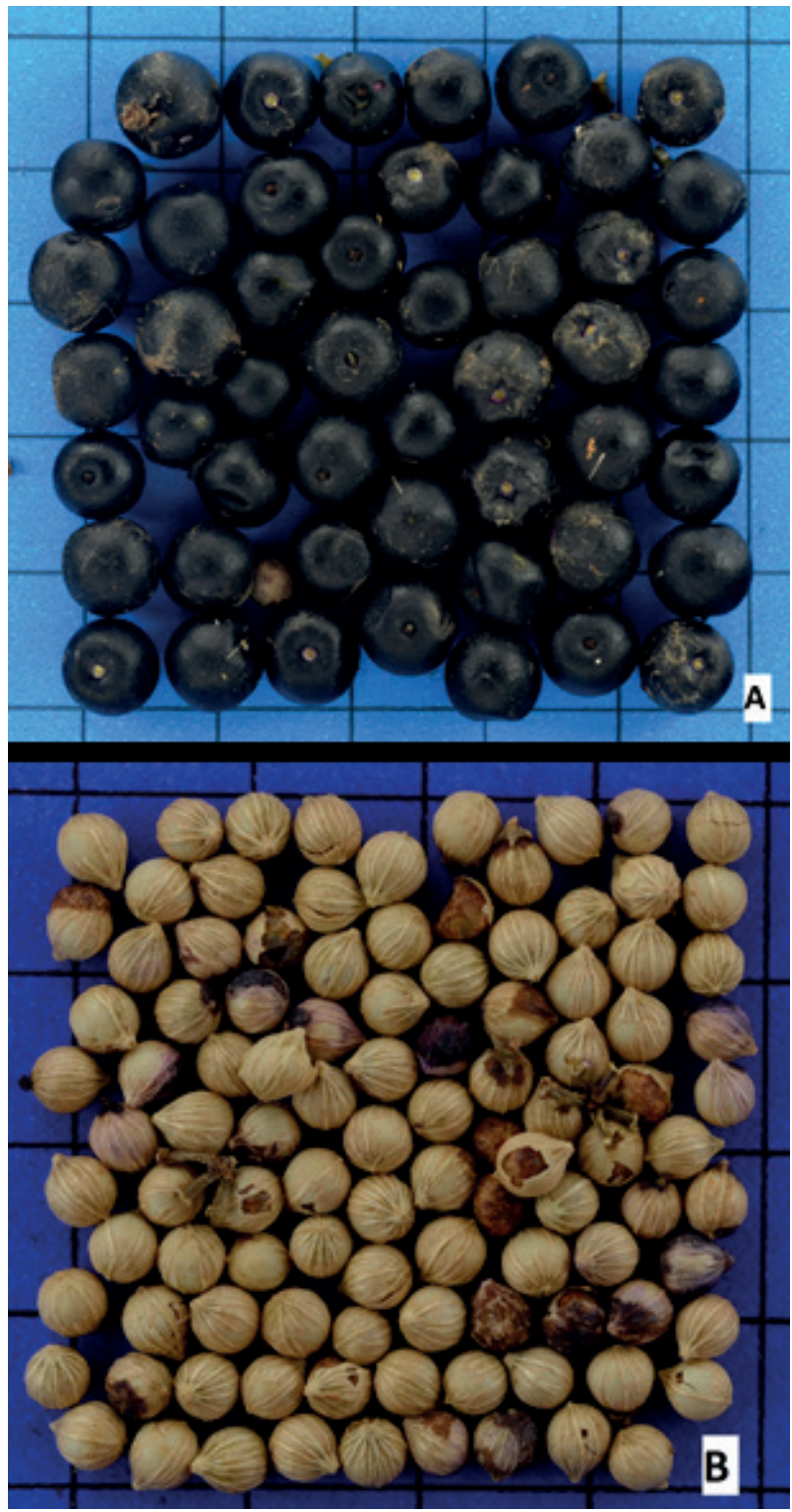

Figs.1 A, B. A. Drupas maduras; B. pirênios de Myrsine parvifolia A. DC. sobre papel centimetrado. Mostruário Científico de Sementes do Banco de Sementes do Jardim Botânico de Porto Alegre.

apresentaram germinação inferior ao teste inicial, e a todos os experimentos posteriores, exceto $300 \mathrm{cfs}$. Também é notável que, durante o período de 120 a 240 dias de armazenamento, os percentuais de geminação estiveram muito próximos àquele dos testes iniciais. Tais resultados sugerem a existência de algum tipo de dormência nas sementes de Myrsine parvifolia.

Comparando-se o desempenho germinativo entre os experimentos cfs versus cfu, é notada uma sensível diferença positiva, da ordem de $4 \%$ na média geral, para experimentos com sementes provenientes do armazenamento em câmara úmida (cfu).

A variação no teor de água das sementes (Fig. 3) apresentou dois padrões bem distintos, correlacionados com a condição de armazenamento. No padrão I, em cfs, ocorreu uma perda de água da ordem de $3 / 4$ do conteúdo total já nos primeiros 60 dias, mantendo-se em torno de $10 \%$ ao longo de todo o experimento; no padrão II, em cfu, a umidade inicial foi mantida, salvo pequenas alterações, girando em torno de $42,5 \%$.

$\mathrm{O}$ teor de água apresentado pelas sementes recémdispersadas, ou seja, após a secagem de maturação ocorrida na fase final de amadurecimento, fornece indícios sobre o possível comportamento frente à dessecação e ao armazenamento das mesmas. No caso de sementes contendo cerca de $40 \%$ de água quando dispersadas, o comportamento intermediário é o mais provável (Castro et al. 2004). Considerando o fluxograma de Hong \& Ellis (1996) para determinação do comportamento de armazenamento de sementes, e considerando os resultados verificados, é possílvel classificar as sementes de M. parvifolia como tendo comportamento intermediário de armazenamento, pois ocorreu a manutenção da germinabilidade, mesmo com a redução do teor de água para níveis entre 10-12\%.

Outras espécies de Myrsine L. já foram avaliadas quanto a comportamento de armazenamento das sementes, sendo que M. umbellata Mart., assim como M. coriacea, apresentaram comportamento ortodoxo de armazenamento (Carvalho 2003, Carvalho et al. 2006).

A dinâmica da emergência de plântulas no momento inicial do experimento, aos seis meses, e após um ano de armazenamento, está nitidamente marcada nos distintos patamares do gráfico representando a Emergência Acumulada de Plântulas (Fig. 4), onde é notável uma resposta mais rápida na germinação das sementes recémcolhidas.

Índices de velocidade de germinação (IVG), normalmente, são valores inversamente proporcionais ao tempo de armazenamento, ao passo que o Tempo Médio de Germinação (TMG) está diretamente relacionado a este. As variações contrárias destes padrões observadas em alguns experimentos deste trabalho, tais como a diminuição do TMG apresentado pelas sementes armazenadas por 360 dias em cfu (Tab. 2), pressupõem que ao redor deste período as sementes de $M$. parvifolia podem apresentar algum mecanismo de aceleração fisiológica, indicando talvez, um período limite para a viabilidade, precedida, possivelmente, por uma investida de energia voltada à germinação. Este fenômeno também pode ser visto nas curvas representativas da emergência acumulada de plântulas dos tratamentos $360 \mathrm{cfs}$ e $360 \mathrm{cfu}$, que se encontram intercaladas entre a curva de emergência dos testes inicial e a curva 180 cfs (Fig. 4).

Variações no TMG \& IVG podem estar relacionadas às mudanças cíclicas entre os estados de dormência $\leftrightarrow$ dormência condicional $\leftrightarrow$ não dormência apresentado por sementes com dormência fisiológica não profunda, conforme descrito por Baskin \& Baskin (1998).

Os patamares das curvas de emergência acumulada de plântulas, a partir das sementes armazenadas por 360 dias, inicialmente, foram superiores, fornecendo respostas mais rápidas que as sementes armazenadas por 180 dias. 
Tabela 1. Teor de água (Ta\%) e percentual de sementes germinadas ( $\mathrm{G} \%)$ de Myrsine parvifolia A. DC. em testes de armazenamento em câmara fria seca (cfs) e câmara fria úmida (cfu). Os valores de p, estatisticamente significativos $(\mathrm{p}<0,05)$ pelo teste do qui-quadrado $\left(\chi^{2}\right)$, estão indicados na tabela. Demais experimentos, estatisticamente não significativos, estão indicados por n.s. O número que antecede a condição de armazenamento (cfs/cfu),indica o período em dias.

\begin{tabular}{|c|c|c|c|c|}
\hline \multicolumn{2}{|c|}{ Tratamentos } & \multirow{2}{*}{$\begin{array}{c}\mathrm{Ta} \\
(\%)\end{array}$} & \multirow{2}{*}{ G (\%) } & \multirow{2}{*}{$\begin{array}{c}\text { Valor } p \\
\quad\left(\chi^{2}\right)\end{array}$} \\
\hline Dias & Condição & & & \\
\hline $\mathrm{Ti}$ & $\mathrm{Ti}$ & 43,4 & 86 & 0,001 \\
\hline \multirow{2}{*}{60} & $\mathrm{cfs}$ & 12,1 & 64 & n.s. \\
\hline & cfu & 46,8 & 61 & n.s. \\
\hline \multirow{2}{*}{120} & $\mathrm{cfs}$ & 11,1 & 83 & 0,007 \\
\hline & cfu & 45,8 & 76 & n.s. \\
\hline \multirow{2}{*}{180} & $\mathrm{cfs}$ & 9,5 & 85 & 0,002 \\
\hline & cfu & 42,8 & 73 & n.s. \\
\hline \multirow{2}{*}{240} & $\mathrm{cfs}$ & 10,1 & 74 & n.s. \\
\hline & cfu & 41,5 & 88 & 0,000 \\
\hline \multirow{2}{*}{300} & $\mathrm{cfs}$ & 6,8 & 42 & 0,000 \\
\hline & cfu & 36,2 & 65 & n.s. \\
\hline \multirow{2}{*}{360} & $\mathrm{cfs}$ & 10,4 & 64 & n.s. \\
\hline & cfu & 42 & 70 & n.s. \\
\hline Média & & 27,6 & 71 & - \\
\hline
\end{tabular}

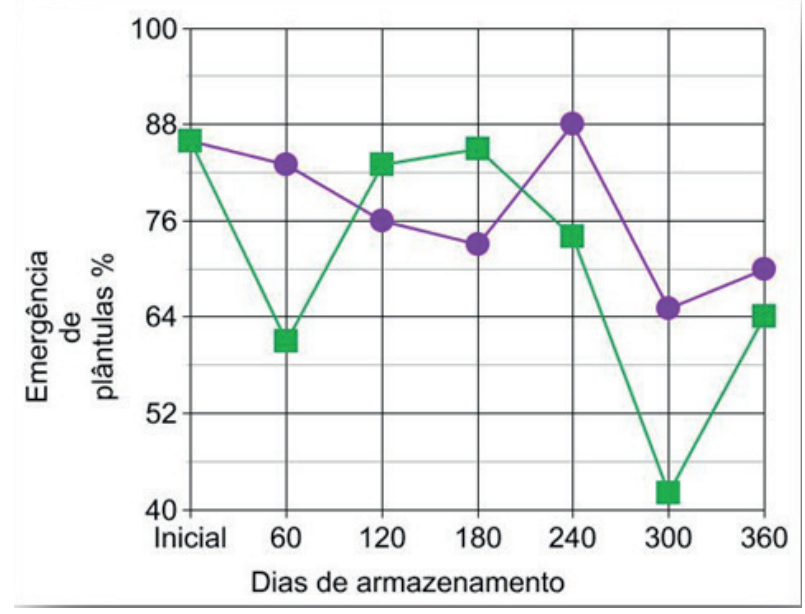

Fig. 2. Percentual de emergência de plântulas a partir de sementes de Myrsine parvifolia A. DC., armazenadas durante 360 dias em câmara fria seca $(\boldsymbol{\bullet})$ e em câmara fria úmida $(\bullet)$.

Contudo, o patamar ao final da avaliação é inferior, ou seja, um menor número de sementes efetivamente germinou no lote que estava armazenado por um ano. Em torno dos 150 dias após a semeadura, não ocorreu mais o estabelecimento de novas plântulas nos lotes armazenados por 360 dias, já para as sementes armazenadas por seis meses o patamar máximo só ficou estável após os 180 dias da semeadura (Fig. 4).

Os experimentos $360 \mathrm{cfs}$ e cfu, estabelecidos em 7 de maio, pouco antes do início do inverno, apresentaram, ao contrário do esperado, um índice de velocidade de germinação superior aos experimentos $180 \mathrm{cfs} / \mathrm{cfu}$, postos a germinar em $1^{\circ} \mathrm{de}$

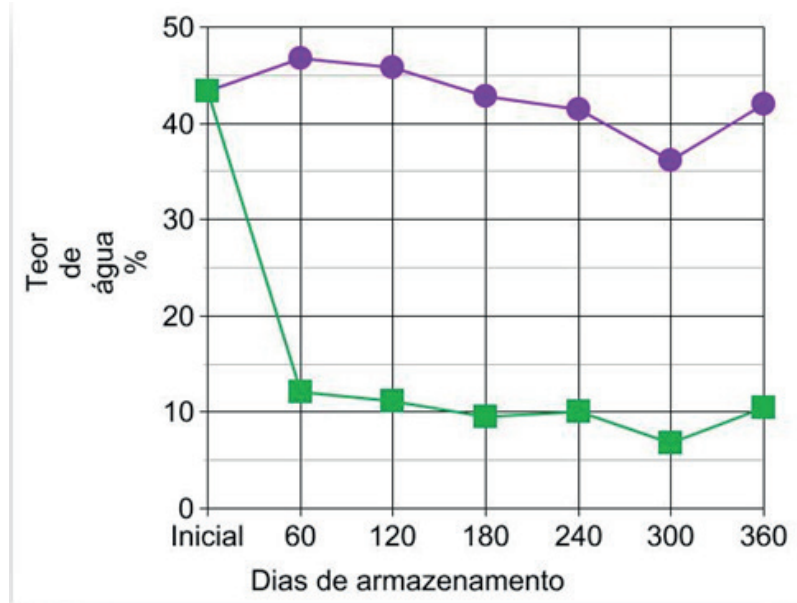

Fig. 3. Variação do teor de água (Ta\%) de sementes de Myrsine parvifolia

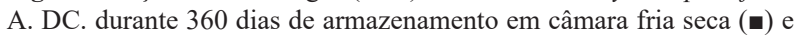
em câmara fria úmida $(\bullet)$.

novembro, antes do início do verão. Novos experimentos com duração superior a 360 dias poderão verificar se há real ocorrência do comportamento de mudanças cíclicas entre os estados de dormência nesta espécie. De forma complementar, experimentos de monitoramento da respiração celular, da mobilização de reservas e do desenvolvimento do embrião também poderão ser bastante esclarecedores do comportamento destas sementes.

O início da emergência de plântulas após a semeadura variou de 40 dias nos testes iniciais a $112 \mathrm{em} 240 \mathrm{cfs} / \mathrm{cfu}$. Em média foram necessários 61 dias para o surgimento das plântulas em ambiente de Casa de Vegetação. A mais provável explicação para o retardo do início da germinação nos experimentos $240 \mathrm{cfs} / \mathrm{cfu}$, estabelecidos no verão, foi a falta de irrigação, atrasando o surgimento das plântulas, porém tal falta d'água, não afetou negativamente a germinação, com resultados acima da média geral (Tab. 1). Um período médio de 61 dias para que ocorra a emergência das plântulas é relativamente longo, quando comparado com o período médio de germinação das espécies florestais apresentadas por Brasil (1998) e por Lorenzi (1998, 2000, 2009). Como anteriormente destacado, a existência de dormência fisiológica, morfo-fisiológica e/ou física nestas sementes é bastante provável, sendo corroborada aqui pelo longo período necessário para o início da germinação.

Quanto à possível dormência, física ou fisiológica, em sementes espécies de Myrsine L., alguns resultados e suposições já foram discutidos em alguns artigos publicados (Joly \& Felippe 1979, Queiroz \& Fiamoncini 1989, Carvalho 1994, Fowler \& Bianchetti 2000). No que diz respeito a dormência fisiológica, Fowler \& Bianchetti (2000) citam M. coriaceae (Sw.) R.Br. ex Roem. \& Schult como uma espécie com dormência endógena, devido a possíveis fatores de mecanismos de inibição fisiológica, que impedem o desenvolvimento do embrião ou este pode encontrar-se imaturo. 


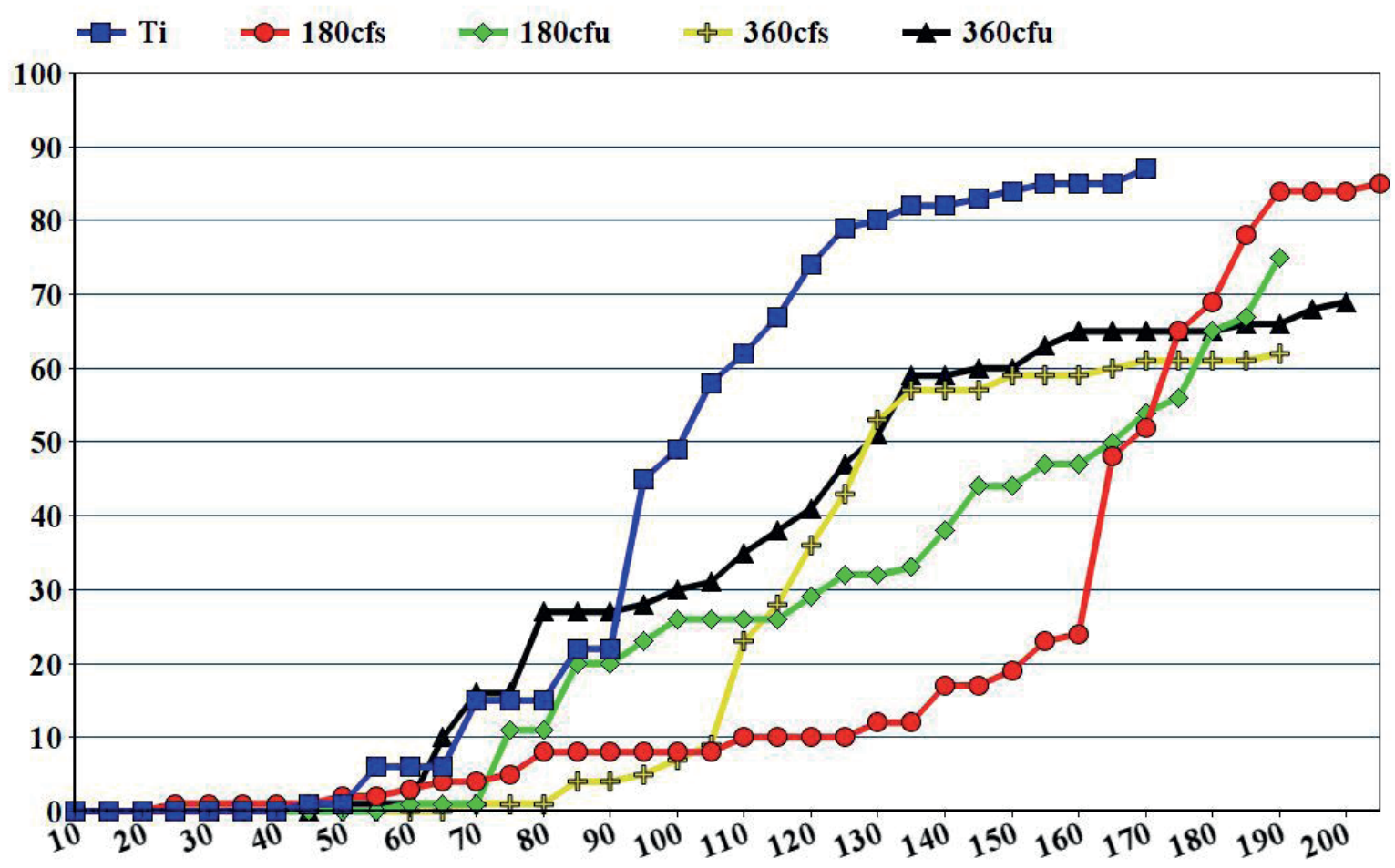

Fig. 4. Emergência acumulada de plântulas de Myrsine parvifolia A. DC. ao longo de 200 dias de avaliação em Casa de Vegetação. Resultados obtidos a partir de sementes recém-colhidas nos testes iniciais ( $\mathrm{Ti} \boldsymbol{\bullet}$ ); armazenadas durante 180 dias câmara fria seca (cfs •) e câmara fria úmida $(\mathrm{cfu} \bullet)$; armazenadas por 360 dias cfs $(+)$ e cfu $(\boldsymbol{\Delta})$.

Tabela 2. Valores de Índice de velocidade de germinação (IVG) e tempo médio de germinação (TMG) das sementes de Myrsine parvifolia A. DC. no teste inicial, aos seis meses (180) e após um ano (360) de armazenamento em câmara fria seca (cfs) e em câmara fria úmida (cfu).

\begin{tabular}{lccc}
\hline Tratamentos & Semeadura & IVG & TMG \\
\hline Ti & Maio & 0.95 & 97.7 \\
$180 \mathrm{cfs}$ & Novembro & 0.61 & 156.0 \\
$180 \mathrm{cfu}$ & Novembro & 0.61 & 131.3 \\
$360 \mathrm{cfs}$ & Maio & 0.6 & 115.2 \\
$360 \mathrm{cfu}$ & Maio & 0.73 & 104.9 \\
\hline
\end{tabular}

No que se refere à dormência física, Queiroz \& Fiamoncini (1989) ressaltam que M. coriaceae e $M$. umbellata Mart. apresentam efetiva dormência devido ao endocarpo, embora este não impeça a embebição das sementes, e que a retirada do mesmo favoreceu a germinação. Resultado semelhante foi encontrado por Joly \& Felippe (1979) para M. guianensis (Aubl. Kuntze), indicando haver dormência devida à resistência mecânica. Também Carvalho (1994) inclui M. coriaceae como sendo uma espécie que apresenta dormência mecânica por produzir sementes com o endocarpo pétreo, cuja rigidez impede a expansão do embrião.

Foi notada a tendência de que, sementes provenientes da câmara fria úmida, apresentaram desenvolvimento de plântulas em intervalos de tempo menor, em relação àquelas provenientes da câmara fria seca. Esta tendência sugere que, as alterações fisiológicas e estruturais, ocorridas durante o armazenamento em condições de $5^{\circ} \mathrm{C}$ e $\approx 80 \%$ $\mathrm{UR}$, foram menos significativas do que aquelas ocorridas no interior da câmara fria seca com $17^{\circ} \mathrm{C}$ e $\approx 45 \%$ UR.

Testes de germinabilidade e emergência de plântulas fornecem dados importantes com relação ao tempo de armazenamento, viabilidade das sementes e cinética dos eventos visíveis, porém são limitados em explicar as razões intrínsecas aos fenômenos observados. Neste sentido, concordamos com a afirmativa de Buckerigde et al. (2004), que faz referência ao estudo da mobilização das reservas em sementes e plântulas, onde experimentos com sementes possam contar com análises paralelas dos eventos, em termos de transcrição, síntese de proteínas e presença de compostos ao longo do período no qual os eventos acontecem. Tais abordagens poderiam explicar as razões possíveis do desempenho apresentado pelo tratamento CV $360 \mathrm{cfs}$, onde sementes armazenadas por 360 dias apresentaram velocidade de emergência superior àquelas armazenadas por 180 dias.

\section{REFERÊNCIAS}

Albuquerque, A.A.E., Lima, H.A., Esteves, V.G., Benevides, C.R. \& Rodarte, A.T.A. 2013. Myrsine parvifolia (Primulaceae) in sandy 
coastal plains marginal to Atlantic rainforest: a case of pollination by wind or by both wind and insects? Brazilian. Journal of Botany 36(1):65-73.

Baskin, C.C. \& Baskin, J.M. 1998. Seeds - Ecology, biogeography and evolution of dormancy and germination. Academic Press, New York. $666 \mathrm{p}$.

Barroso, G.M., Morin, M.P., Peixoto, A.L. \& Ichaso, C.L.F. 1999. Frutos e sementes: morfologia aplicada à sistemática de dicotiledôneas. Editora da Universidade Federal de Viçosa, Viçosa. 443 p.

Borguetti, F. \& Ferreira, A.G. 2004. Interpretação de resultados de germinação. In Germinação do básico ao aplicado (A.G. Ferreira \& F.A. Borguetti, orgs.). Artmed, Porto Alegre, p. 209-222.

Brasil. 2009. Ministério da Agricultura, Pecuária e Abastecimento. Regras para análise de sementes. Ministério da Agricultura, Pecuária e Abastecimento - Secretaria de defesa agropecuária, Brasília. 399p.

.1998. Instituto brasileiro do meio ambiente e dos recursos naturais renováveis - Sementes Florestais: Colheita, beneficiamento e armazenamento. Programa Florestal - Projeto In Instituto Brasileiro do Meio Ambiente, Brasília. 26p.

Buckeridge, M.S., Santos, H.P., Tiné, M.A. \& Aidar, M.P.M. 2004. Mobilização de reservas. In Germinação do básico ao aplicado (A.G. Ferreira \& F.A. Borguetti, orgs.). Artmed, Porto Alegre, p. 163-185

Carvalho, L.R., Silva, E.A.A., Davide, A.C. 2006. Classificação de sementes florestais quanto ao comportamento no armazenamento. Revista Brasileira de Sementes 28(2):15-25.

Carvalho, P.E.R. 1994. Espécies florestais brasileiras: recomendações silviculturais, potencialidades e uso da madeira. Embrapa, Brasília, $640 \mathrm{p}$.

2003. Espécies arbóreas brasileiras. Embrapa informação tecnológica, Brasília; Embrapa Florestas, Colombo, Paraná. 1039 p

Castro, R.D., Bradford, K.J. \& Hilhorst, H.W.M. 2004. Embebição e reativação do metabolismo. In Germinação: do básico ao aplicado (,A.G. Ferreira \& F.A. Borguetti, orgs.) Artmed, Porto Alegre, p. 149-162.

Fowler, J.A.P. \& Bianchetti, A. 2000. Dormência em sementes florestais. Embrapa Floresta, Colombo, Série Documentos nº 40. 27 p.

Freitas, M.F. Myrsine. Lista de Espécies da Flora do Brasil. Jardim Botânico do Rio de Janeiro. Disponível em: <http://floradobrasil. jbrj.gov.br/jabot/floradobrasil/FB10223>. Acessado em 05.06.2014.

Hong, T.D. \& Ellis, R.H. 1996. A protocol to determine seed storage behavior. International Plant Genetic Resources Institute, Roma, Technical bulletin $\mathrm{n}^{\circ} 1.62 \mathrm{p}$.
Jesus, S. \& Monteiro-Filho, E.L.A. 2007. Frugivoria por aves em Schinus terebinthifolius (Anacardiaceae) e Myrsine coriaceae (Myrsinaceae). Revista Brasileira de Ornitologia 15(4):5885-591.

Joly, C.A. \& Felippe, G.M. 1979. Dormência das sementes de Rapanea guianensis Aubl. Revista Brasileira de Botânica 2(1):1-6.

Jung-Mendaçolli, S.L. \& Bernacci, L.C. 2001. Myrsinaceae da APA de Cairuçu, Parati (Rio de Janeiro, Brasil). Rodriguesia 52(81):49-94.

Lima Junior, M.J. 2011. Manual de procedimentos para análise de sementes florestais: Associação Brasileira de Tecnologia de Sementes, Londrina. $83 \mathrm{p}$.

Lorenzi, H. 1998. Árvores brasileiras: manual de identificação e cultivo de plantas arbóreas nativas do Brasil. Editora Plantarum, São Paulo. $370 \mathrm{p}$.

.2000. Árvores brasileiras: manual de identificação e cultivo de plantas arbóreas nativas do Brasil. Editora Plantarum, São Paulo. $368 \mathrm{p}$.

Lorenzi, H. 2009. Árvores brasileiras: manual de identificação e cultivo de plantas arbóreas nativas do Brasil . Editora Plantarum, São Paulo. $384 \mathrm{p}$.

Lorenzi, H. \& Gonçalves, E.G. 2011. Morfologia vegetal: Organografia e dicionário ilustrado de morfologia das plantas vasculares $2^{\mathrm{a}}$ edição. Editora Plantarum, São Paulo. 544 p.

Martin, A.C. 1946. The comparative internal morphology of seeds. The American Midland Naturalist 36(3):513-660.

Pascotto, M.C. 2007. Rapanea ferruginea (Ruiz. \& Pav.) Mez. (Myrsinaceae) como uma importante fonte alimentar para as aves em uma mata de galeria no interior de São Paulo. Revista Brasileira de Zoologia 254(3):735-741.

Queiroz, H. \& Fiamoncini, D.I. 1989. Dormência de sementes de Rapanea ferruginea (R. \& P.) Mez e Rapanea umbellata (Mart. Ex A. Dl.) Mez. In Anais do $2^{\circ}$ Simpósio Brasileiro Sobre Tecnologia de Sementes Florestais, São Paulo. 248 p.

Reitz, R., Klein, R.M. \& Reis, A. 1988. Projeto Madeira do Rio Grande do Sul. Governo do Estado do Rio Grande do Sul, Secretaria da Agricultura e Abastecimento, Porto Alegre. 525 p.

Rego, S.S., Santos, A.F. \& Medeiros, A.C.S. 2009. Fungos associados aos frutos e sementes de capororoca (Myrsine ferruginea) Myrsinaceae. Pesquisa Florestal Brasileira 58:87-90.

Vaccaro, S., Longui, S.J. \& Brena, D.A. 1999. Aspectos da composição florística e categorias sucessionais do estrato arbóreo de três subseres de uma floresta estacional decidual no município de Santa Tereza RS. Ciência Florestal 9(1):1-18. 